Houtum, L. van, Rijken, M., Heijmans, M., Groenewegen, P. Self-management support needs of patients with chronic illness: do needs for support differ according to the course of illness?

\begin{tabular}{|l|l|}
\hline $\begin{array}{l}\text { Postprint } \\
\text { Version }\end{array}$ & 1.0 \\
\hline Journal website & http://www.pec-journal.com/article/S0738-3991(13)00346-7/fulltext \\
\hline Pubmed link & http://www.ncbi.nlm.nih.gov/pubmed/24029582 \\
\hline DOI & 10.1016/j.pec.2013.08.021
\end{tabular}

This is a NIVEL certified Post Print, more info at http://www.nivel.eu

\title{
Self-management support needs of patients with chronic illness: Do needs for support differ according to the course of illness?
}

\author{
Lieke Van Houtum ${ }^{\mathrm{A},}{ }^{*}$, Mieke RiJken ${ }^{\mathrm{A}}$, Monique Heijmans ${ }^{\mathrm{A}}$, Peter Groenewegen ${ }^{\mathrm{A}, \mathrm{B}}$ \\ ${ }^{a}$ NIVEL - Netherlands Institute for Health Services Research, Utrecht, The Netherlands \\ ${ }^{\mathrm{b}}$ Utrecht University, Department of Sociology and Department of Human Geography, \\ Utrecht, The Netherlands
}

\begin{abstract}
A B S T R A C T
Objective: To determine whether chronically ill patients' needs for selfmanagement support depend on their course of illness.

Methods: Cross-sectional and longitudinal linear regression analyses were conducted using data from 1300 patients with chronic disease(s) who participated in a nationwide Dutch panel-study. Self-management support needs were assessed by the Patient Assessment of Self-management Tasks questionnaire (PAST). Course of illness was operationalized as: illness duration, patients' perception of the course of illness and changes in self-rated general health (RAND-36).

Results: Self-management support needs are not related to illness duration. Patients who perceive their illness as episodic and/or progressively deteriorating have greater self-management support needs than patients who perceive their illness as stable. Deterioration of self-rated health is related to increased support needs. The effect of the course of illness on support needs depends on the type of self-management activities.
\end{abstract}

Conclusion: How chronically ill patients perceive the course of illness and actual changes in self-rated health are predictive for their need for support for self-management activities. Illness duration is not.

Practice implications: Helping patients to self-manage should not be confined to the first years after diagnosis. Healthcare providers should be alert to patients' own perceptions of their course of illness and health status.

\section{INTRODUCTION}

Self-management of chronic illness has been widely recognized as an essential part of chronic illness care, as it empowers patients and improves health outcomes $[1,2]$. 
Houtum, L. van, Rijken, M., Heijmans, M., Groenewegen, P. Self-management support needs of patients with chronic illness: do needs for support differ according to the course of illness?

Patient Education and Counseling: 2013, 93(3), 626-632

Effective self-management consists of monitoring one's condition and adapting cognitive, behavioral and emotional responses to maintain a satisfactory quality of life [3]. However, many patients have difficulty managing their chronic illness properly [4]. Recognition of these difficulties has led to the development of many self-management support programs over recent decades [4-6]. Nevertheless, evaluating how successful these programs are generally shows only modest positive effects [4-8]. One of the difficulties of developing effective self-management support is that the population of patients with chronic conditions is very diverse. As a result, some patients might need support taking medication as prescribed, while others need support exercising sufficiently.

Understanding patients' needs for self-management support might improve the effectiveness of self-management support. So far, research on chronically ill patients' needs for self-management support has been scarce.

The need for self-management support can be studied from the perspective of coping with stressful situations. This perspective views chronic illness as a major life event characterized by a number of recurrent stressful situations that pose serious challenges to adaptation [9-12]. As chronic illnesses change over time, patients with chronic conditions continuously have to adapt to the stressful situation that is appraised at that moment [10]. These constant adaptations trigger the need for support. A better understanding of the individual course of illness could be helpful in determining the support needs of chronically ill patients. The purpose of this study is therefore to examine chronically ill patients' needs for self-management support through the course of their illness.

There are several ways to describe an individual's course of illness. First, the course of illness can be described by the duration of a patient's chronic illness, for instance the time since diagnosis. A second, more subjective way is starting from patients' own perceptions of their course of illness. According to the Common Sense Model of Leventhal and colleagues, subjective perceptions of a chronic disease rather than its objective characteristics will encourage health-related behavior of patients [13,14]. Therefore, how patients perceive their course of illness might be a good indicator of their self-management support needs. A third way is describing changes in self-rated health over time. As mentioned before, patients with chronic conditions continuously have to adapt to stressful situations, which may trigger the need for support $[10,11]$. Changes in self-rated health could be considered an indication of the stress they experience.

In this study, we will examine to what extent the course of a chronic illness, operationalized in the three ways described above, relates to chronically ill patients' needs for support for various self- management activities. Our research questions are:

1. How does illness duration relate to the needs for self- management support of chronically ill patients?

2. How does the patients' perceived course of illness relate to the needs for selfmanagement support of chronically ill patients?

3. How do changes in self-rated health (over one year) relate to the needs for self-management support of chronically ill patients?

In line with a broad definition of self-management, e.g. [3,15], we assume that selfmanagement comprises a variety of activities. Therefore, we distinguish, in 
Houtum, L. van, Rijken, M., Heijmans, M., Groenewegen, P. Self-management support needs of patients with chronic illness: do needs for support differ according to the course of illness?

Patient Education and Counseling: 2013, 93(3), 626-632

accordance with Bayliss and colleagues, four types of self-management activities patients might need support with, namely medical management, commu- nication with healthcare providers, coping with the consequences of having a chronic illness, and making lifestyle changes [16]. Because of the different challenges involved, we will study the extent to which patients perceive a need for support separately for these four types of activities.

To guide our research, we formulated three hypotheses.

1. Based on focus group sessions we held over the last years with several groups of patients with chronic diseases (e.g. diabetes, COPD), we noticed that self-management support seems to be provided mainly during the first years after diagnosis of a chronic disease. However, a longer illness duration can provoke new stressful situations. The Chronic Illness Trajectory Framework shows that symptoms can become uncontrollable over time, forcing patients to change their adaptive regimen $[17,18]$. Support may therefore be equally necessary later, as patients proceed through the course of illness. The first hypothesis in our study is that the need for support is not smaller for patients who were diagnosed longer ago than for patients who have more recently been diagnosed with a chronic disease ( $0-3$ years).

2. The perceived course of illness may be stable, episodic and/or progressive [19]. Patients who experience their illness as stable may not feel a need to change the way they manage their illness, whereas patients who perceive their illness as episodic and/or progressively deteriorating may need to alter their health regimen continuously, which can bring uncertainty and stress [18]. Previous research has demonstrated an association between poor functioning and the believe that the illness has a cyclical character [20]. We expect that perceiving the course of illness as episodic and/or progressively deteriorating relates to a greater need for self-management support than a course of illness perceived as stable.

3. Furthermore, changes in self-rated health demand a great deal from patients' adaptive abilities [21-23]. A relapse or complication may cause stress and subsequently create a need for support, whereas an experienced improvement in health may reduce the need for self-management support. We hypothesized that deterioration in self-rated general health relates to increased selfmanagement support needs, whereas improvement relates to decreased selfmanagement support needs.

\section{METHODS}

\subsection{Participants}

Data were analyzed from the National Panel of people with chronic illness or disability (NPCD), a nationwide prospective panel study on the consequences of chronic illness in the Netherlands [24,25]. Participants with chronic disease were recruited from more than a hundred general practices (random samples of general practices drawn from the Dutch registration of general practices [26]). Patients were selected using the following criteria: diagnosis of a somatic chronic disease by a certified medical practitioner, aged 2:15 years, not permanently institutionalized, aware of the diagnosis, not terminally ill (life expectancy $>6$ months according to the 
Houtum, L. van, Rijken, M., Heijmans, M., Groenewegen, P. Self-management support needs of patients with chronic illness: do needs for support differ according to the course of illness? Patient Education and Counseling: 2013, 93(3), 626-632

GP), mentally capable of participating, and sufficient mastery of Dutch [24,25]. Annually, 500 new panel members are selected via the standardized procedure to replace panel members who withdrew or who had participated for the maximum term of four years. NPCD is registered with the Dutch Data Protection Authority; all data are collected and handled in accordance with the privacy protection guidelines of the Authority.

\subsection{Data collection}

We used data that were collected at three different points in time. In April 2012, a questionnaire about the needs for self- management support and self-perceived general health was sent to the panel members. A total of 1688 patients diagnosed with a chronic disease completed this questionnaire (response $=82 \%$ ). Sociodemographic information and patients' perception of their course of illness was assessed at inclusion as well as medical data of panel members as provided by their GPs. To answer our final question, we also used data about the needs for selfmanagement support and self-perceived general health from the questionnaire of April 2011. In total, 1300 participants filled in the questionnaire of 2011 as well as the questionnaire of 2012.

\subsection{Operationalization}

\subsubsection{Course of illness}

Illness duration (in years) was calculated based on the date of diagnosis of the (first) chronic disease, which was extracted from the GP files. For our analyses, we divided illness duration into six categories ( $0-3$ years, $3-5$ years, $5-10$ years, $10-15$ years, 15-20 years and 20 years or more). We did not use age as a continuous variable, as we did not expect support needs to change gradually for each additional year. How patients perceive their course of illness was based on two questions posed at inclusion: whether patients considered their course of illness as episodic and whether they considered it as progressively deteriorating. Both items were scored on a 3-point scale ( $1=$ 'not at all', 2 = 'to some extent' and $3=$ 'to a large extent'). For the analyses, the categories 'to some extent' and 'to a large extent' were combined. Based on these two items the variable 'patient perceived course of illness' was created with four values: (1) stable (respondents who answered 'not at all' for both items); (2) episodic; (3) progressively deteriorating; and (4) episodic and progressively deteriorating.

Patients' self-rated general health was measured by the general health scale of the RAND-36 Short Health Status Survey [27].

The scale score was calculated based on five items and rescored to range from low (1 $=$ poor general health $)$ to high $(100=$ excellent health $)$. Cronbach's alpha for the general health scale was .81 in both 2011 and 2012. Changes in self-rated general health were calculated by subtracting the individual score for 2011 from the individual 2012 score. This score was divided into three categories based on half the standard deviation [28]: “deteriorated health”' (-100 to -7), “no change in health” (7 to 7$)$ and “'improved health”'(7-100).

\subsubsection{Self-management support needs}


Houtum, L. van, Rijken, M., Heijmans, M., Groenewegen, P. Self-management support needs of patients with chronic illness: do needs for support differ according to the course of illness?

Patient Education and Counseling: 2013, 93(3), 626-632

To assess patients’ need for self-management support, we used the Patient Assessment of Self-management Tasks questionnaire (PAST) [29]. In this questionnaire, patients indicate to what extent they feel they need to perform several self-management tasks and to what extent they feel a need for support with these tasks, both answered on a 4-point scale ranging from 0 (never) to 3 (always). For example, how often do you need to take medication as prescribed and how often do you need support with this? Patients who do not consider a specific self-management task are assumed to have no need for support in this task. In accordance with the description of self-management activities by Bayliss and colleagues [16], we distinguished four types of self-management activities people might need support with: (1) medical management (5 items), e.g. taking medication correctly or selfmonitoring of symptoms; (2) communication with healthcare providers (4 items), e.g. understanding information given by healthcare providers and participating in decision making; (3) coping with the consequences of the illness (5 items), e.g. coping with pain and an uncertain future; and (4) making lifestyle changes (4 items), e.g. exercising sufficiently or eating healthily. The scales were constructed by summing the scores on the separate items belonging to the scale. Participants had to fill in at least three items per scale in order to get a scale score. Needs for selfmanagement support were assessed in the questionnaires of 2011 and 2012. Cronbach's alphas for the four scales were .72 and .73 (medical management in 2011 and 2012 respectively), .80 (communication), .83 (coping) and.72 (making lifestyle changes, all both years).

\subsubsection{Socio-demographic and illness characteristics}

We included the following socio-demographic characteristics: age, gender, highest level of education and living situation. In addition, we included the type of chronic disease and the presence of more than one chronic disease (multi-morbidity). The chronic diseases of participants were registered by their GPs using the International Classification of Primary Care [30]. Examples of registered diseases are heart failure, COPD and multiple sclerosis.

\section{[TABLE 1][TABLE 2]}

\subsection{Statistical analyses}

Descriptive analyses were performed to provide information on the characteristics of the study sample. Associations between illness duration, patient perceived course of illness and self-rated general health were explored by linear regression analyses and one-way ANOVA, followed by a Bonferroni post hoc test.

To test the first two hypotheses, we conducted linear regression analyses. The first model tested the effects of several socio- demographic and illness characteristics (see Section 2.3.3) on the needs for self-management support (dependent variable). The second model tested the effect of illness duration (independent variable) on selfmanagement support needs (dependent variable), controlling for the sociodemographic and illness characteristics. The third model tested the effect of patientperceived course of illness (independent variable) on self-management support needs (dependent variable) controlling for the socio-demographic and illness characteristics. We tested these models for all four support needs scales. 
Houtum, L. van, Rijken, M., Heijmans, M., Groenewegen, P. Self-management support needs of patients with chronic illness: do needs for support differ according to the course of illness?

Patient Education and Counseling: 2013, 93(3), 626-632

To test the third hypothesis, we also conducted linear regression analyses. First, we tested the effect of the change in self-rated general health between 2011 and 2012 (independent variable) on the change in the need for self-management support (dependent variable). As we expected that the initial self-rated health might influence this relation, we also conducted analyses which included the interaction term of selfrated general health in 2011 and changes in self-rated general health between 2011 and 2012 as an independent variable. In these analyses we did not control for sociodemographic and illness characteristics, as we measured these variables only once (at inclusion). Again, we tested these models for all four support needs scales separately. We conducted single-level regression analyses instead of multilevel analyses, since intra-class correlations showed hardly any clustering of support needs within general practices, the original sampling framework (mean .01). In addition, the likelihood ratio test did not show that multilevel analyses had an advantage over ordinary regression analyses. All analyses were performed using Stata 12.0.

\section{RESULTS}

\subsection{The study population}

Table 1 presents socio-demographic and illness characteristics of the study population in 2012. The mean age of the respondents was 61 years. Asthma (15\%), COPD (15\%), diabetes (12\%) and cardiovascular disease (12\%) were the most common chronic diseases within the sample. Almost half the respondents (48\%) had been diagnosed with more than one chronic disease. Four percent of the respondents were diagnosed less than three years ago, $12 \%$ three to five years ago, one third (34\%) five to ten years ago and almost half (48\%) ten years or longer ago. More than a third of the respondents (38\%) perceived the course of their illness as stable. The others perceived their illness as episodic (21\%), progressively deteriorating (10\%) or both (31\%). The mean general health score of the study population was 53.6 in 2011 and 52.1 in 2012. The mean change in self-rated health scores was small (-1.7), but the wide standard deviation (14.0) indicates that the perceived general health of some participants did change substantially between 2011 and 2012.

\subsection{Associations between course-of-illness variables}

The three course-of-illness variables appear to be related to some extent. Patients who perceived their illness to be stable or episodic had been diagnosed significantly more recently (11.4 and 11.2 years ago on average) than patients who perceived their illness as both episodic and progressively deteriorating (13.1 years ago on average). Patients who perceived their illness as stable reported the highest perceived health score (64.3), while patients who perceived the course of their illness as episodic and progressively deteriorating reported the lowest perceived health score (37.9). Furthermore, patients' self-rated health was related to illness duration; the longer patients were ill, the lower their perceived health score was. Changes in self-rated health over one year were neither related to illness duration nor to patients' perceived course of illness. 
Houtum, L. van, Rijken, M., Heijmans, M., Groenewegen, P. Self-management support needs of patients with chronic illness: do needs for support differ according to the course of illness?

Patient Education and Counseling: 2013, 93(3), 626-632

\subsection{Effects of illness duration and patients' perceived course of illness on the need for self-management support}

Model 1 in Table 2 demonstrates that older people, women, lower educated people, people who live alone and people who have more than one chronic disease had higher support needs. These effects differed for the four types of self-management activities. Model 2 shows that when comparing patients who have been diagnosed relatively recently ( $0-3$ years) to patients who were diagnosed longer ago, no differences were found in their needs for support. This applied to all four types of self-management activities.

Model 3 shows a significant positive effect of patients' perceived course of illness on the needs for self-management support. This implies that the need for support with all types of self-management tasks was greater for patients who perceived their illness as episodic and/or progressively deteriorating than for those who perceived their illness as stable. In particular, patients who perceived the course of their illness to be both episodic and progressively deteriorating reported a greater need for selfmanagement support. The effects of perceiving one's illness as episodic and/or progressively deteriorating were greatest for the need for support in coping. The adjusted R2 shows that model 3 explained substantially more of the variance in the needs for self-management support than the first two models.

\subsection{Effects of changes in self-rated health on changes in support needs}

On average, the needs for self-management support of chronically ill patients barely changed between 2011 and 2012, but the wide ranges suggest that the support needs did change substantially for some patients (Table 3). Table 4 (model 1) shows

\section{[TABLE 3, TABLE 4 FIGURE 1]}

that self-management support needs increased when the selfrated general health deteriorated over the last year, while support needs decreased when perceived general health improved. This effect is illustrated in Fig. 1. The effects of changes in perceived health were the highest for support needs related to 'coping' and the lowest for support needs related to 'medical management' and 'lifestyle changes'. The percentages of variance explained by the change in self-rated health were low. The second model in Table 4 shows that there was no significant interaction effect of patients' initial self-rated health score in 2011. This means that the relationship between changes in self-rated health and changes in needs for selfmanagement support was linear.

\section{DISCUSSION AND CONCLUSION}

\subsection{Discussion}

Patients with chronic illness have different needs for self- management support. The purpose of this study was to examine whether the needs for self-management support of chronically ill patients depend on their individual course of illness. Consistent 
Houtum, L. van, Rijken, M., Heijmans, M., Groenewegen, P. Self-management support needs of patients with chronic illness: do needs for support differ according to the course of illness?

Patient Education and Counseling: 2013, 93(3), 626-632

with our first hypothesis, we found that the needs for self- management support are not lower for patients who have been

diagnosed many years ago than for recently diagnosed patients.

This can be explained by the fact that the manifestation of a chronic illness often changes over time, which may involve continuously altering self-management tasks. Adaptation to a new health regimen is therefore not only a characteristic of the first phase of illness but also of later phases. This is in accordance with findings of other studies that showed that the demands of the situation when living with a chronic illness vary from one illness stage to another [22,23].

Furthermore, patients' perceptions of the course of their illness relate to their selfmanagement support needs. Patients who perceive their course of illness as episodic and/or progressively deteriorating have greater needs for self-management support than patients who perceive their illness as stable. This is in line with our second hypothesis. Other studies have shown that an unpredictable course of illness leads to feelings of lower self- efficacy [31,32]. Patients might experience their selfmanagement as failing. The impact on patients' self-efficacy beliefs may be one of the mechanisms through which patients' perceived course of illness influences their need for self-management support.

In line with our third hypothesis, we found a significant effect of a change in selfrated health over one year on changes in self- management support needs.

Deterioration of self-rated health relates to increasing self-management support needs, while improvement relates to a decrease. Other studies demonstrated that patients' perceived health status influences their ability to perform self-management. For example, physical limitations and symptoms, such as pain and fatigue, are common barriers to self- management for people with chronic conditions [33,34]. In addition, deterioration of health might cause feelings of loss of control as patients feel that their self-management strategies have failed, whereas experiencing health improvement could affirm patients' self-management.

Interestingly, the effects of patients' perceived course of illness and change in their self-rated health on the need for self- management support differ depending on the type of self- management activities involved. In particular, the need for support in coping with the consequences of chronic illness and in communicating satisfactorily with healthcare providers depend more on patients' perceived course of illness and changes in their perceived health than support needs related to medical management and making lifestyle changes. It might be that more subjective measures of the course of illness (patients' perceptions) impact more on psychological aspects of self-management such as coping and communicating than on more practical aspects such as medical management and making lifestyle changes.

To the best of our knowledge, this is the first study that explores chronically ill patients' needs for self-management support as a function of their individual course of illness. Although this study was primarily cross-sectional, we also performed longitudinal analyses (over a period of one year) to explain changes in the needs for self-management support of patients with chronic illness. One year is however a short period of time for changes to occur. This might explain why, in general, the changes in self-rated health and in the needs for self-management support were moderate, and the explained variation in the changes in support needs was low. We are aware that a longer follow-up period would have been better. Nevertheless, by combining the cross-sectional results with the results of the longitudinal analyses this 
Houtum, L. van, Rijken, M., Heijmans, M., Groenewegen, P. Self-management support needs of patients with chronic illness: do needs for support differ according to the course of illness?

Patient Education and Counseling: 2013, 93(3), 626-632

study provides relevant insights into the self-management support needs of chronically ill patients.

Furthermore, we did not control for the type and amount of self- management support that patients already received. In the questionnaire we asked respondents to report whether they needed '(extra) support' with certain self-management tasks. Therefore, the fact that people report a need for support cannot be interpreted as that they did not receive any support. We can only conclude that they still have unmet support needs. Unfortunately, it is not possible to get a reliable estimate of the actual amount of support patients receive, as patients experience the provided support differently.

Another limitation is that we assessed patient's perceived course of illness at inclusion, while the needs for self-management support were assessed in April 2011 and 2012. The time between inclusion of the respondent and the data collection of April 2012 varies between 17 days and 4 years (mean 2.0). Knowing that illness perceptions are mainly shaped in the first period of illness $[35,36]$ and that most of our respondents were already ill for a substantial amount of years at inclusion (mean 12.0 years), we assume that their perceptions about the course of illness had become quite stable at that time. Furthermore, patient's perceived course of illness was assessed with only two, self-developed items. Despite this, we used these items because of their ability to distinguish four different 'courses' of chronic illness: stable, episodic, progressive and both. An indication of the validity of the two combined items was found by the significant association with the IPQ-R timeline scale [37] included in the questionnaire of April 2012: people who perceive their illness as episodic or both episodic and progressive reported a significantly stronger cyclical timeline than people who perceived their course of illness as progressive or stable.

Finally, this study only partly explains the variation in self- management support needs of patients with chronic illness. The results show that several aspects of patients' lives that are related to different social roles and resources, such as their age, gender, education and living situation, are important as well. Further research is needed to explore how patients' course of life and their everyday activities interfere with their needs for self-management support. This may provide more insight into the mechanisms that underlie the self-management support needs of patients with chronic illness.

\subsection{Conclusion}

Chronically ill patients' own perceptions on the course of their illness as well as actual changes in self-rated health are predictive for their needs for support for several self-management activities, whereas illness duration is not. Both the amount of self- management support and the type of self-management activities patients need support with are related to the individual course of illness.

\subsection{Practical implications}

First, healthcare providers need to be aware that self- management support needs of patients with chronic illness can arise or increase at any moment as the illness progresses. Healthcare providers should therefore pay attention continuously to patients' perceptions of their course of illness and their perceptions of health. 
Houtum, L. van, Rijken, M., Heijmans, M., Groenewegen, P. Self-management support needs of patients with chronic illness: do needs for support differ according to the course of illness? Patient Education and Counseling: 2013, 93(3), 626-632

Second, health-care providers need to have knowledge about self-management support. Support should not only include practical help and advice regarding the medical management of chronic disease and lifestyle issues, but also support for effective communication with healthcare providers and patients' coping with their chronic illness in daily life. This is especially important for patients whose illness is characterized by progressive deterioration and/or by episodic fluctuations in the frequency and severity of symptoms. Finally, the variation in self- management support needs shows that there is an urge for tailored interventions, which take the changeability of patients' support needs into account.

\section{Acknowledgements}

This study formed part of the research program 'National Panel of people with chronic illness or disability', which is financed by the Netherlands Ministry of Public Health, Welfare and Sports and the Netherlands Ministry of Social Affairs and Employment. This study is also part of a Ph.D. project that is financed by the Netherlands Ministry of Education, Culture and Science. We would like to thank Lucas van der Hoek for his statistical advice.

\section{REFERENCES}

[1] Griffiths C, Foster G, Ramsay J, Eldridge S, Taylor S. How effective are expert patient (lay led) education programs for chronic disease? Considerable hyper- bole has surrounded the UK expert patient programme, and it has received considerable fundingbut will its impact meet expectations? Brit Med J 2007;334:1254-6.

[2] Clark N. Management of chronic disease by patients. Annu Rev Public Health 2003;24:289-313.

[3] Barlow J, Wright C, Sheasby J, Turner A, Hainsworth J. Self-management approaches for people with chronic conditions: a review. Patient Educ Couns 2002;48:177-87.

[4] Newman S, Steed L, Mulligan K. Self-management interventions for chronic illness. Lancet 2004;364:1523-37.

[5] Rijken M, Jones M, Heijmans M, Dixon A. Supporting self-management. In: Nolte E, McKee M, editors. Caring for people with chronic conditions. A health system perspective. Berkshire, UK: Open University Press; 2008. p. 116-42.

[6] Warsi A, Wang P, LaValley M, Avorn J, Solomon D. Self-management education programs in chronic disease: a systematic review and methodological critique of the literature. Arch Intern Med 2004;164:1641-9.

[7] Gardetto N. Self-management in hearth failure: where have we been and where should we go? J Multidiscip Healthc 2011;4:39-51.

[8] Ursum J, Rijken M, Heijmans M, Cardol M, Schellevis F. Zorg voor chronisch zieken: Organisatie van zorg, zelfmanagement, zelfredzaamheid en partici- patie. Utrecht: NIVEL; 2011.

[9] De Ridder D, Schreurs K, Bensing J. Adaptive tasks, coping and quality of life and chronically III patients: the cases of Parkinson's disease and chronic fatigue syndrome. J Health Psychol 1998;3:87-101.

[10] Heijmans M, Rijken M, Foets M, De Ridder D, Schreurs K, Bensing J. The stress of being chronically III: from disease-specific to task-specific aspects. J Behav Med 2004;27:255-71.

[11] Moos RH, Schaeffer JA. The crisis of physical illness: an overview and concep- tual approach. Coping with physical Illness Vol 2 New perspectives, New York: Plenum Press; 1984.

[12] Zautra AJ. Investigations of ongoing stressful situations among those with chronic illness. Am J Community Psychol 1996;24:697-717. 
Houtum, L. van, Rijken, M., Heijmans, M., Groenewegen, P. Self-management support needs of patients with chronic illness: do needs for support differ according to the course of illness?

Patient Education and Counseling: 2013, 93(3), 626-632

[13] Leventhal $\mathrm{H}$, Diefenbach $\mathrm{M}$. Using common sense to understand treatment adherence and affect cognition interactions. Cog Therapy Res 1992;16: 143-63.

[14] Leventhal H, Meyer D, Nerenz D. The common sense representation of illness danger. In: Rachman S, editor. Medical psychology. New York, NY: Pergamon; 1980. p. 7-30.

[15] Clark NM, Becker MH, Janz NK, Lorig K, Rakowski W, Anderson L. Self- management of chronic disease by older adults. A review and questions for research. J Aging Health 1991;3:3-27.

[16] Bayliss E, Steiner J, Fernald D, Crane L, Main D. Descriptions of barriers to self- care by persons with comorbid chronic diseases. Ann Fam Med 2003;1:15-21.

[17] Corbin JM, Strauss A. A nursing model for chronic illness management based upon the trajectory framework. Sch Inq Nurs Pract Int J 1991;5:155-74.

[18] Burton CR. Re-thinking stroke rehabilitation: the Corbin and Strauss chronic illness trajectory framework. J Adv Nurs 2000;32:595-602.

[19] Newby NM. Chronic illness and the family life-cycle. J Adv Nurs 1996;23: 786-91.

[20] Scharloo M, Baatenburg de Jong RJ, Langeveld TPM, Van Velzen-Verkaik E, Doorn-op den Akker MM, Kaptein AA. Quality of life and illness perceptions in patients with recently diagnosed head and neck cancer. Head Neck 2005; 17:1-16.

[21] Schipper K, Nierse C, Hene' R, Van Zadelhoff E, Van Griendt J, Abma T. Leven met een nierziekte: Ervaringen van nierpatie" nten en hun naasten [Living with kidney disease: experiences of kidney patients and their family]. Den Haag Lemma 2010.

[22] Heim E, Valach L, Schaffner L. Coping and psychological adaption: Iongitudinal effects over time and stages of breast cancer. Psychosom Med 1997;59:408- 18.

[23] Fugate Woods N, Yates BC, Primomo J. Supporting families during chronic illness. J Nurs Scholarsh 1989;21:46-50.

[24] Rijken M, Bensing J. Het nationaal Patie" ntenpanel Chronisch Zieken. Een onderzoeksinfrastructuur voor patie" ntgericht onderzoek [The national panel of patients with chronic diseases. An infrastructure for patient-centered research]. Utrecht: NIVEL; 2000.

[25] Rijken M, Groenewegen P. Money does not bring well-being, but it does help! The relationship between financial resources and life satisfaction of chroni- cally ill mediated by social deprivation and loneliness. J Community Appl Soc Psychol 2008;18:39-53.

[26] Hingstman L, Kenens R. Cijfers uit de registratie van huisartsen: peiling 2009 [Figures from the registration of GPs: survey 2009]. Utrecht: NIVEL; 2009.

[27] Van der Zee KI, Sanderman R. Het meten van de algemene gezondheidstoe- stand met de RAND-36. Een handleiding [Measuring general health status with the RAND-36. A guide]. Groningen: Rijksuniversiteit Groningen; 1993.

[28] Norman GR, Sloan JA, Wyrwich KW. Interpretation of changes in health- related quality of life: the remarkable university of half a standard deviation. Med Care 2003;41:582-92.

[29] Van Houtum L, Rijken PM, Heijmans MJWM, Groenewegen PP. Perceptions of selfmanagement tasks and support needs of people with chronic illness: generic or diseasespecific?; 2012, submitted for publication.

[30] Lamberts H, Wood M. ICPD. International classification of primary care. Oxford: Oxford University Press; 1987.

[31] Shnek ZM, Foley FW, LaRocca NG, Gordon WA, DeLuca J, Schwartzman HG, et al. Helplessness, self-efficacy, cognitive distortions, and depression in multiple sclerosis and spinal cord injury. Ann Behav Med 1997;19: 287-94.

[32] Rapley P, Fruin DJ. Self-efficacy in chronic illness: the juxtaposition of general and regimen-specific efficacy. Int J Nurs Pract 1999;5:209-15.

[33] Bair MJ, Matthias MS, Nyland KA, Huffman MA, Stubbs DL, Kroenke K, et al. Barriers and facilitators to chronic pain self-management: a qualitative study of primary care patients with comorbid musculoskeletal pain and depression. Pain Med 2009;10:1280-90.

[34] Jerant AF, Von Friederichs-Fitzwater MM, Moore M. Patients' perceived bar- riers to active self-management of chronic conditions. Patient Educ Couns 2005;57:300-7.

[35] Petrie KJ, Cameron LD, Ellis CJ, Buick D, Weinman J. Changing illness percep- tions after myocardial infarction: an early intervention randomized controlled trial. Psychosom Med 2002;64:580-6.

[36] Rutter CL, Rutter BR. Longitudinal analysis of the illness representation model in patients with irritable bowel syndrome (IBS). J Health Psychol 2007;2: 141-8. 
Houtum, L. van, Rijken, M., Heijmans, M., Groenewegen, P. Self-management support needs of patients with chronic illness: do needs for support differ according to the course of illness?

Patient Education and Counseling: 2013, 93(3), 626-632

[37] Moss-Morris R, Weinman J, Petrie K, Horne R, Cameron L, Buick D. The revised illness perception questionnaire (IPQ-R). Psychol Health 2002;17:1-16.

\section{TABLES AND FIGURE}

Table 1

Descriptive characteristics of the study population 2012 .

\begin{tabular}{|c|c|c|c|c|c|}
\hline & $n$ & Percentage & Mean & Range & $\mathrm{SD}$ \\
\hline \multicolumn{6}{|l|}{ Patients characteristics } \\
\hline Age & 1684 & & 61.2 & $16-93$ & 15.1 \\
\hline Female & 1684 & 54 & & & \\
\hline Cohabiting & 1673 & 77 & & & \\
\hline Education level & 1639 & & & & \\
\hline Lower $^{\mathrm{a}}$ & & 34 & & & \\
\hline Intermediate $^{\mathrm{b}}$ & & 43 & & & \\
\hline Higher $^{c}$ & & 23 & & & \\
\hline \multicolumn{6}{|l|}{ Objective disease characteristics } \\
\hline Diagnosis index disease & 1684 & & & & \\
\hline Cardiovascular disease & & 12 & & & \\
\hline Asthma & & 15 & & & \\
\hline COPD & & 15 & & & \\
\hline Musculoskeletal disorder & & 12 & & & \\
\hline Cancer & & 5 & & & \\
\hline Diabetes mellitus & & 12 & & & \\
\hline Neurological disease & & 7 & & & \\
\hline Gastrointestinal disease & & 4 & & & \\
\hline Other chronic disease & & 19 & & & \\
\hline Multi-morbidity present & 1684 & 48 & & & \\
\hline Illness duration (years post-diagnosis) & 1659 & & 12.0 & $.4-66$ & 8.9 \\
\hline Less than 3 years & & 4 & & & \\
\hline $3-5$ years & & 12 & & & \\
\hline $5-10$ years & & 34 & & & \\
\hline $10-15$ years & & 25 & & & \\
\hline $15-20$ years & & 12 & & & \\
\hline 20 years or longer & & 13 & & & \\
\hline \multicolumn{6}{|l|}{ Patient-reported illness characteristics } \\
\hline Patient's perceived course of illness & 1468 & & & & \\
\hline Stable & & 38 & & & \\
\hline Episodic & & 21 & & & \\
\hline Progressive deterioration & & 10 & & & \\
\hline Episodic and progressive & & 31 & & & \\
\hline Perceived health in 2011 & 1217 & & 53.8 & $0-100$ & 20.7 \\
\hline Perceived health in 2012 & 1538 & & 52.1 & $0-100$ & 20.5 \\
\hline Change in perceived health $2011-2012$ & 1138 & & -1.7 & $-55-60$ & 13.99 \\
\hline Deteriorated & & 31 & & & \\
\hline No change & & 46 & & & \\
\hline Improved & & 23 & & & \\
\hline
\end{tabular}

${ }^{a}$ Lower $=$ primary school or only vocational training.

${ }^{\mathrm{b}}$ Intermediate $=$ high school or intermediate vocational training.

${ }^{\mathrm{c}}$ Higher $=$ college or university. 
Houtum, L. van, Rijken, M., Heijmans, M., Groenewegen, P. Self-management support needs of patients with chronic illness: do needs for support differ according to the course of illness?

Patient Education and Counseling: 2013, 93(3), 626-632

Table 2

Regression analyses testing the effect of illness duration and patient's perceived course of illness on self-management support needs of patients with chronic illness 2012

\begin{tabular}{|c|c|c|c|c|c|c|c|c|c|c|c|c|}
\hline \multirow{2}{*}{$\begin{array}{l}\text { Self-management support needs } \\
2012\end{array}$} & \multicolumn{3}{|c|}{ Medical management } & \multicolumn{3}{|c|}{ Communication } & \multicolumn{3}{|l|}{ Coping } & \multicolumn{3}{|l|}{ Lifestyle } \\
\hline & $\begin{array}{l}\text { Model } 1 \\
\beta\end{array}$ & $\begin{array}{l}\text { Model } 2 \\
\beta\end{array}$ & $\begin{array}{l}\text { Model } 3 \\
\beta\end{array}$ & $\begin{array}{l}\text { Model } 1 \\
\beta\end{array}$ & $\begin{array}{l}\text { Model } 2 \\
\beta\end{array}$ & $\begin{array}{l}\text { Model } 3 \\
\beta\end{array}$ & $\begin{array}{l}\text { Model } 1 \\
\beta\end{array}$ & $\begin{array}{l}\text { Model } 2 \\
\beta\end{array}$ & $\begin{array}{l}\text { Model } 3 \\
\beta\end{array}$ & $\begin{array}{l}\text { Model } 1 \\
\beta\end{array}$ & $\begin{array}{l}\text { Model } 2 \\
\beta\end{array}$ & $\begin{array}{l}\text { Model } 3 \\
\beta\end{array}$ \\
\hline Age & $.13^{*}$ & $.13^{* *}$ & $.12^{*}$ & $.17^{* \prime}$ & $.17^{* *}$ & $.17^{* *}$ & $.08^{* \prime}$ & $.08^{\circ}$ & $.08 *$ & -.00 & -.00 & .01 \\
\hline Gender (ref = male) & .01 & .01 & -.01 & $.08 *$ & $.08 *$ & $.06^{\circ}$ & $.12 *$ & $.12 *$ & $.09^{* *}$ & .01 & .00 & -.01 \\
\hline \multicolumn{13}{|l|}{ Educational level } \\
\hline Low (ref) & - & - & - & - & - & - & - & - & - & - & - & - \\
\hline Intermediate & $-.07^{*}$ & $-.07^{*}$ & -.05 & $-.09^{*}$ & $-.09 *$ & -.06 & -.02 & -.02 & .02 & -.02 & -.01 & -.00 \\
\hline Higher & $-.10^{* *}$ & $-.10^{* *}$ & $-.11^{*}$ & $-.12^{*}$ & $-.12^{*}$ & $-.12^{*}$ & -.01 & -.01 & -.02 & -.06 & -.06 & -.07 \\
\hline $\begin{array}{l}\text { Living situation } \\
\text { (ref= living alone) }\end{array}$ & -.02 & -.02 & -.01 & -.05 & -.05 & -.03 & $-.08 *$ & -.08 & $-.07^{*}$ & $-.06^{\circ}$ & $-.07^{*}$ & -.05 \\
\hline $\begin{array}{l}\text { Multi-morbidity } \\
\text { (ref= one disease) }\end{array}$ & $.07^{\circ}$ & $.07^{\circ}$ & $.07^{*}$ & $.06^{*}$ & .04 & .04 & $.06^{\circ}$ & .04 & .04 & .04 & .06 & .05 \\
\hline \multicolumn{13}{|l|}{ Index disease } \\
\hline Cardiovascular disease (ref) & - & - & - & - & - & - & - & - & - & - & - & - \\
\hline Asthma & -.00 & -.01 & .01 & -.03 & -.04 & -.03 & -.04 & -.05 & -.03 & -.03 & -.03 & -.03 \\
\hline COPD & -.04 & -.04 & -.04 & -.01 & -.01 & -.03 & .01 & .01 & -.01 & .03 & .02 & .02 \\
\hline Musculoskeletal disorder & -.01 & -.01 & -.03 & .01 & .00 & -.03 & .05 & .05 & .02 & -.01 & -.01 & -.03 \\
\hline Cancer & .02 & .02 & .03 & .03 & .03 & .04 & .02 & .02 & .02 & -.01 & -.01 & .01 \\
\hline Diabetes mellitus & .06 & .05 & .03 & .03 & .03 & .01 & .03 & .02 & .02 & $.08^{\circ}$ & $.08^{\circ}$ & .06 \\
\hline Neurological disease & $.07^{\circ}$ & .06 & .06 & $.07^{\circ}$ & .06 & .05 & $.11^{*}$ & $.10^{* *}$ & $.10^{* *}$ & .03 & .04 & .02 \\
\hline Gastrointestinal disease & -.02 & -.02 & -.03 & -.01 & -.01 & -.02 & .02 & .02 & .01 & .01 & .01 & -.01 \\
\hline Other chronic disease & -.01 & -.01 & -.00 & -.03 & -.03 & -.03 & -.01 & -.02 & .01 & -.01 & -.01 & -.00 \\
\hline \multicolumn{13}{|l|}{ Duration of illness } \\
\hline $0-3$ years (ref) & & - & & & - & & & - & & & - & \\
\hline $3-5$ years & & .02 & & & -.00 & & & .02 & & & -.04 & \\
\hline $5-10$ years & & .07 & & & .08 & & & .09 & & & -.06 & \\
\hline $10-15$ years & & .03 & & & .03 & & & .05 & & & -.11 & \\
\hline $15-20$ years & & .05 & & & .05 & & & .09 & & & -.08 & \\
\hline 20 years or longer & & .05 & & & .08 & & & .08 & & & -.05 & \\
\hline \multicolumn{13}{|l|}{$\begin{array}{l}\text { Patient's perceived } \\
\text { course of illness }\end{array}$} \\
\hline Stable (ref) & & & - & & & - & & & - & & & \\
\hline Episodic & & & $.09^{*-}$ & & & $.14^{* *}$ & & & $.16 *$ & & & .16 \\
\hline Progressive deterioration & & & $.08 *$ & & & $.10^{*}$ & & & $.13^{*}$ & & & .12 \\
\hline Episodic and progressive & & & $.27^{*}$ & & & $.33^{*}$ & & & $.41^{*}$ & & & .24 \\
\hline Adjusted $R^{2}$ & $.04 *$ & $.03^{*}$ & $.09^{*}$ & $.06^{*}$ & $.06 *$ & $.15^{* *}$ & $.04^{*}$ & $.04 *$ & $.18^{* *}$ & $.01^{\circ}$ & $.01^{\circ}$ & .06 \\
\hline
\end{tabular}

Table 3

Description of the changes in self-management support needs between 2011 and 2012.

\begin{tabular}{lrrlll}
\hline $\begin{array}{l}\text { Changes in self-management } \\
\text { support needs 2011-2012 }\end{array}$ & $N$ & Mean & SD & Min & Max \\
\hline Medical management & 1022 & .002 & .40 & -2.2 & 2.35 \\
Communication & 993 & .002 & .43 & -1.75 & 2.25 \\
Coping with consequences & 1030 & -.009 & .40 & -2.2 & 2.2 \\
Lifestyle changes & 969 & .002 & .49 & -2.25 & 2.25 \\
\hline
\end{tabular}


Houtum, L. van, Rijken, M., Heijmans, M., Groenewegen, P. Self-management support needs of patients with chronic illness: do needs for support differ according to the course of illness?

\section{Table 4}

Regression analyses testing the effect of changes in perceived general health on changes in self-management support needs of patients with chronic illness between 2011 and 2012 .

\begin{tabular}{|c|c|c|c|c|}
\hline $\begin{array}{l}\text { Changes in } \\
\text { self-management } \\
\text { support needs } \\
2011-2012\end{array}$ & $\begin{array}{l}\text { Medical } \\
\text { management } \\
\beta\end{array}$ & Communication & Coping & Lifestyle \\
\hline \multicolumn{5}{|l|}{ Model 1} \\
\hline $\begin{array}{l}\text { Changes in perceived } \\
\text { health }\end{array}$ & -.08 & $-.11^{*}$ & -.14 & $-.08^{*}$ \\
\hline Adjusted $R^{2}$ & .00 & $.01^{*}$ & $.02^{*}$ & $.01^{*}$ \\
\hline \multicolumn{5}{|l|}{ Model 2} \\
\hline $\begin{array}{l}\text { Changes in perceived } \\
\text { health }\end{array}$ & -.14 & $-.26^{* *}$ & $-.30^{*}$ & -.02 \\
\hline $\begin{array}{l}\text { Perceived health } \\
\text { in } 2011\end{array}$ & .01 & $.08^{\circ}$ & .03 & .02 \\
\hline $\begin{array}{l}\text { Change in health } \\
\text { in } 2011\end{array}$ & .07 & .19 & .17 & -.05 \\
\hline Adjusted $R^{2}$ & .00 & $.02^{*}$ & $.02^{*}$ & .00 \\
\hline
\end{tabular}

- Significant difference at $p<.05$.

- Significant difference at $p<.01$. 
Houtum, L. van, Rijken, M., Heijmans, M., Groenewegen, P. Self-management support needs of patients with chronic illness: do needs for support differ according to the course of illness?

Patient Education and Counseling: 2013, 93(3), 626-632

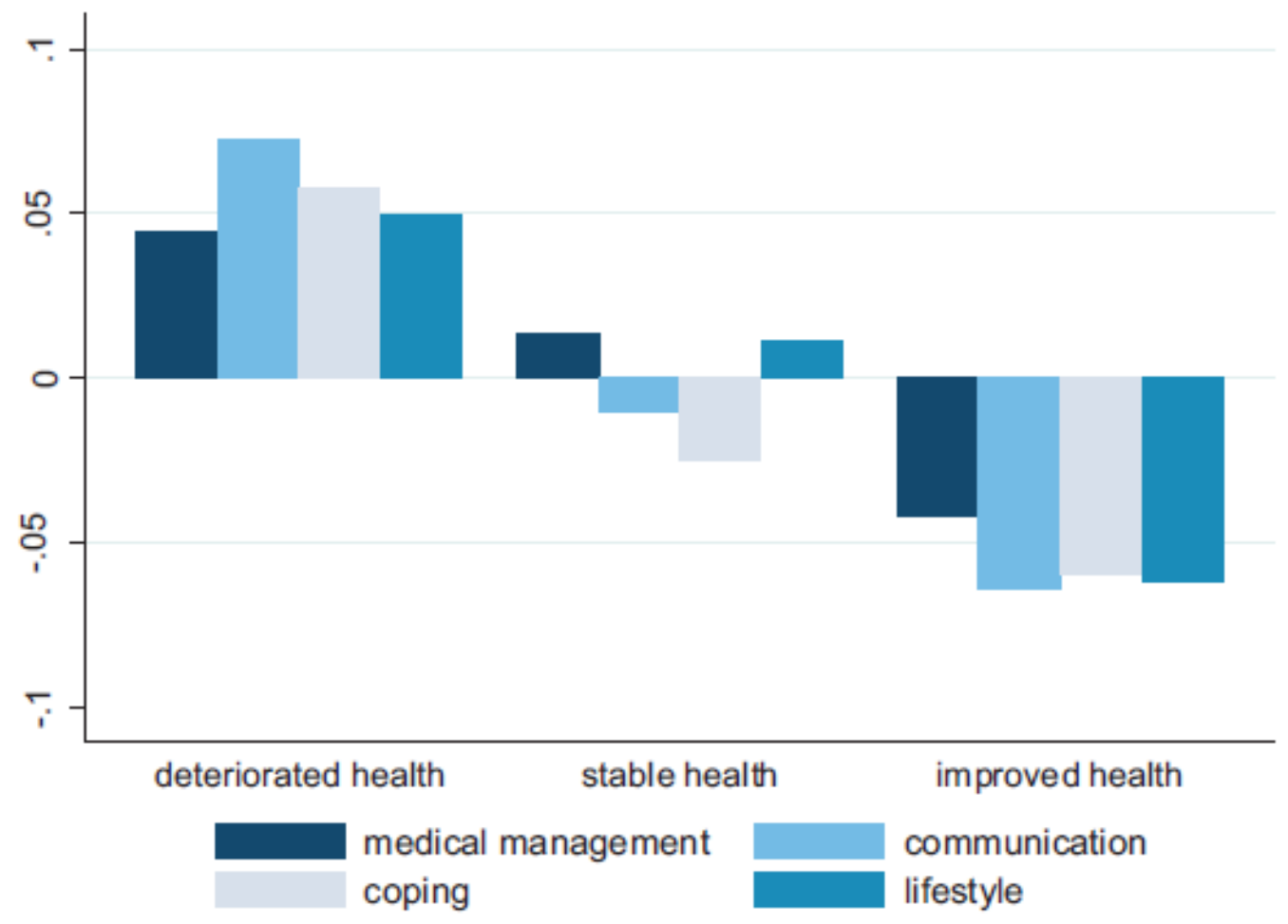

Fig. 1. Changes in the needs for self-management support between 2011 and 2012 according to changes in perceived health (mean scores). 